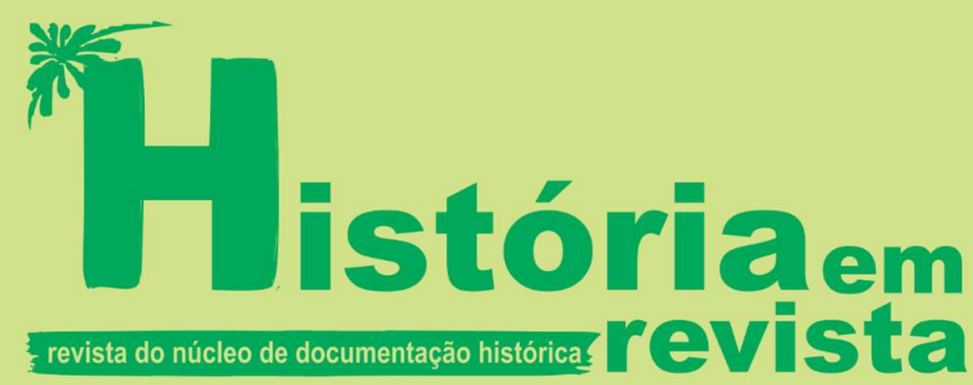

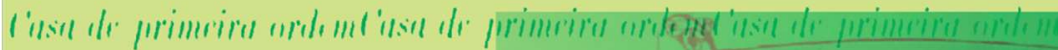

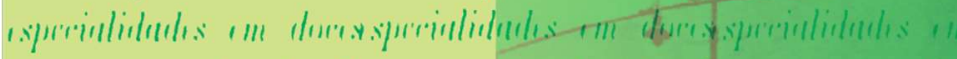

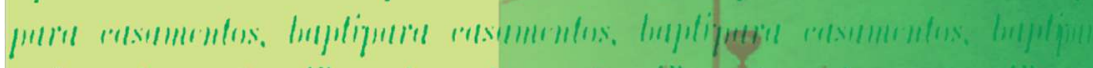

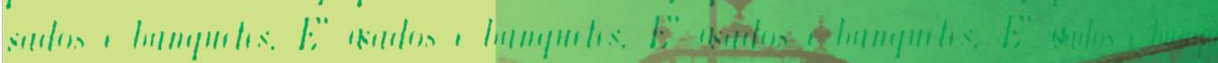

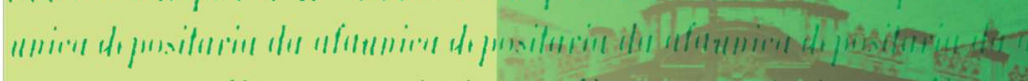

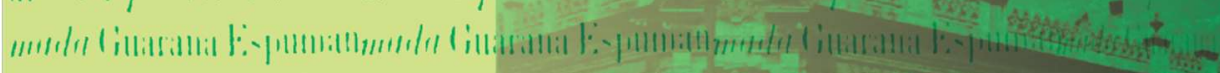

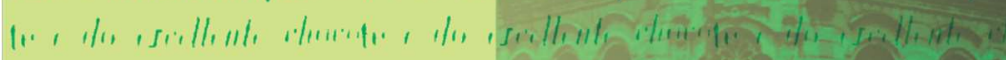

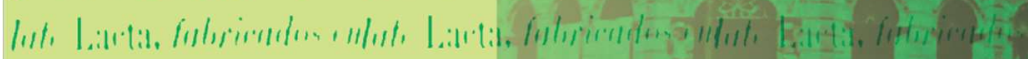

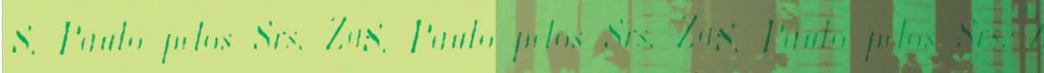

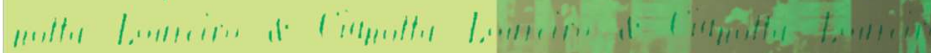

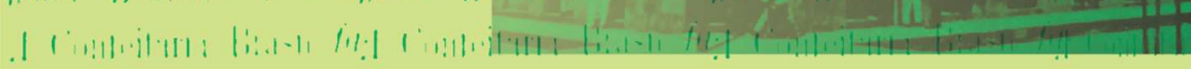




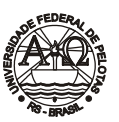

Obra publicada pela Universidade Federal de Pelotas Reitor: Pedro Rodrigues Curi Hallal Vice-Reitor: Luis Isaías Centeno do Amaral

Chefe de Gabinete: Aline Elias Lamas

Pró-Reitor de Graduação: Maria de Fátima Cóssio

Pró-Reitor de Pesquisa e Pós-Graduação: Flávio Fernando Demarco

Pró-Reitor de Extensão e Cultura: Francisca Ferreira Michelon

Pró-Reitor de Planejamento e Desenvolvimento: Otávio Martins Peres

Pró-Reitor Administrativo: Ricardo Hartlebem Peter

Pró-Reitor de Infra-estrutura: Julio Carlos Balzano de Mattos

Pró-Reitor de Assuntos Estudantis: Mário Renato de Azevedo Jr.

Pró-Reitor de Gestão Pessoas: Sérgio Batista Christino

\section{CONSELHO EDITORLAL}

Representante das Ciências Agronômicas: Guilherme Albuquerque de Oliveira Cavalcanti (Titular), Cesar Valmor Rombaldi (suplente) e Fabrício de Vargas Arigony Braga (suplente) | Representantes da Área das Ciências Exatas e da Terra: Adelir José Strieder (titular) e Juliana Pertille da Silva (suplente) | Representante da Área das Ciências Biológicas: Raquel Ludke (suplente) | Representante da Área das Engenharias e Computação: Darci Alberto Gatto | Representantes da Área das Ciências da Saúde: Claiton Leoneti Lencina (titular) e Giovanni Felipe Ernst Frizzo (suplente) | Representante da Área das Ciências Sociais Aplicadas: Célia Helena Castro Gonsales | Representante da Área das Ciências Humanas: Charles Pereira Pennaforte e Guilherme Camargo Massaú (suplente) | Representantes da Área das Linguagens e Artes: Josias Pereira da Silva (titular) e Maristani Polidori Zamperetti (suplente)

\section{INSTITUTO DE CIÊNCLAS HUMANAS}

Diretor: Prof. Dr. Sidney Gonçalves Vieira

Vice-Diretor: Prof. Dr. Sebastião Peres

\section{NÚCLEO DE DOCUMENTACÃO HISTÓRICA}

Coordenadora:

Prof ${ }^{a}$ Dra. Lorena Almeida Gill

Membros do NDH:

Prof ${ }^{a}$ Dra. Beatriz Ana Loner

Prof ${ }^{a}$ Dra. Lorena Almeida Gill

Prof. Dr. Paulo Ricardo Pezat

Prof. Dr. Aristeu Elisandro Machado Lopes

Técnico Administrativo:

Paulo Luiz Crizel Koschier

HISTÓRIA EM REVISTA - Publicação do Núcleo de Documentação Histórica

Comissão Editorial:

Prof. Dr. Aristeu Elisandro Machado Lopes

Prof ${ }^{a}$ Dra. Beatriz Ana Loner

Prof ${ }^{a}$ Dra. Lorena Almeida Gill

Prof. Dr. Paulo Ricardo Pezat

Conselho Editorial:

Prof ${ }^{a}$ Dra. Helga I. Landgraf Piccolo (UFRGS)

Prof. Dr. René Gertz (UFRGS) (PUCRS)

Prof. Ms. Mario Osorio Magalhães (UFPel)

Prof. Dr. Temístocles A. C. Cezar (UFRGS)

Profa. Dra. Beatriz Teixeira Weber (UFSM)

Prof ${ }^{a}$. Dra. Maria Cecília V. e Cruz (UFBA)

Prof. Dr. Marcelo Badaró Mattos (UFF)

Profa. Dra. Joan Bak (Univ. Richmond - USA)

Prof. PhD Pablo Alejandro Pozzi (Universidad de Buenos Aires).

Prof. Tommaso Detti (Università Degli Studi di Siena)

Editor: Prof. Dr. Aristeu Elisandro Machado Lopes

Editoração e Capa: Paulo Luiz Crizel Koschier

Editora e Gráfica Universitária

R Lobo da Costa, 447 - Pelotas, RS - CEP 96010-150 |

Fone/fax: (53) 32278411

e-mail: editora@ufpel.edu.br

\section{Impresso no Brasil}

Edicão: 2017

ISSN - 1516-2095

Dados de catalogação na fonte: Aydê Andrade de Oliveira - CRB - 10/864

História em revista / publicação do Núcleo de Documentação Histórica. Instituto de Ciências Humanas. Universidade Federal de Pelotas. v.23, (dez. 2017). - Pelotas: Editora da UFPel, 2017.

$1 \mathrm{v}$.

Anual

ISSN 1516-2095

1. História - Periódicos. I. Núcleo de Documentação Histórica. Instituto de Ciências Humanas. Universidade Federal de Pelotas. CDD 930.005

\section{Indexada pela base de dados Worldcat Online Computer Library Center}

\section{PEDE-SE PERMUTA} WE ASK FOR EXCHANGE

UFPel/NDH/Instituto de Ciências Humanas

Rua Cel. Alberto Rosa, 154

Pelotas/RS - CEP: 96010-770

Caixa Postal 354

Fone: (53) 32843208

\section{http://wp.ufpel.edu.br/ndh/} e-mail:ndh.ufpel@gmail.com 


\title{
LITERATURA E HISTÓRIA: POSSÍVEIS APROXIMAÇÕES
}

\author{
LITERATURE AND HISTORY: POSSIBLE APROXIMATIONS
}

Raíssa Cardoso Amaral ${ }^{1}$

\begin{abstract}
Resumo: Este artigo irá discorrer sobre a relação interdependente entre a literatura e a história, tendo como objeto de análise o romance A Festa do Bode (2000), de Mario Vargas Llosa. Ao especificar o gênero literário romance com o adjetivo "histórico" torna-se visível uma tensão, pois literatura e história são formas de expressão do conhecimento inicialmente consideradas díspares e antagônicas. Desse modo, como frequentemente ocorre com os conceitos da área das Ciências Humanas, torna-se difícil encontrar uma definição estanque de romance histórico, visto que os conceitos de literatura e história sofreram - e ainda sofrerão - modificações ao longo dos tempos.
\end{abstract}

Palavras-chave: literatura; história; romance histórico; metaficção historiográfica

O romance é um gênero literário de complexa definição, pois há uma liberdade em sua forma narrativa, isto é, não existe um único modelo a ser seguido. Ao especificar o romance com o adjetivo "histórico" torna-se visível uma tensão, pois literatura e história são duas formas de expressão do conhecimento inicialmente consideradas como díspares e antagônicas. Desse modo, como frequentemente ocorre com os conceitos da área das Ciências Humanas, torna-se difícil encontrar uma definição estanque de romance histórico, visto que os conceitos de literatura e história sofreram modificações ao longo dos tempos2.

György Lukács reiteradamente nos é apresentado, pela crítica, como o autor fundamental para a compreensão do que vem a ser um romance histórico, devido sua publicação de O Romance Histórico, em 1937. Lukács afirma que a forma clássica de romance histórico surgiu no início do século XIX, com Walter Scott. Além disso, seus grandes sucessores foram Balzac e Tolstói. Nas palavras do filósofo húngaro,

No romance histórico, portanto, não se trata do relatar contínuo dos grandes acontecimentos históricos, mas do despertar ficcional dos homens que os protagonizaram. Trata-se de figurar de modo vivo as motivações sociais e

1 Mestre em Letras, área de concentração em Literatura Comparada - Universidade Federal de Pelotas (UFPel). E-mail para contato: issa.amaral@hotmail.com

2 Uma versão ampliada dessa discussão está publicada na dissertação Festas manchadas de sangue e violência: literatura e história em A Festa, de Ivan Angelo e A Festa do Bode, de Mario Vargas Llosa de minha autoria, sob orientação do Professor Dr. Alfeu Sparemberger (UFPel). 
humanas a partir das quais os homens pensaram, sentiram e agiram de maneira precisa, retratando como isso ocorreu na realidade histórica (LUKÁCS, 2011, p. $60)$.

No romance histórico há um posicionamento pessoal, ideológico e cultural por trás do discurso/narração, afinal, os sujeitos, assim como os textos, não podem ser considerados neutros tampouco ingênuos (WEINHARDT, 1994). A interpretação defendida pela pesquisadora e professora Marilene Weinhardt (1994) vai ao encontro das ideias de Lukács: no romance histórico há um impacto poético que surge dos personagens que vivenciaram as experiências históricas. Nas palavras da própria pesquisadora, "Ao romance histórico não interessa repetir os grandes acontecimentos, mas ressuscitar poeticamente os seres humanos que viveram essa experiência" (WEINHARDT, 1994, p. 51).

Assim como Marilene Weinhardt, Fredric Jameson (2004) também comenta o fato de György Lukács ser referência para os estudos a respeito do romance histórico. Porém, ao contrário das formulações de Lukács, Jameson solicita que olhemos para Walter Scott não como o primeiro escritor de romance histórico, mas como um produtor de drama de costumes. Para Jameson seria então, Guerra e Paz, de Tolstói, o grande exemplar de romance histórico. Jameson também assinala que toda e qualquer convenção acerca da noção de romance histórico pode e deve ser questionada, como fica explícito no trecho a seguir:

O romance histórico [...] não será a descrição dos costumes e valores de um povo em um determinado momento de sua história (como pensava Manzoni); não será a representação de eventos históricos grandiosos (como quer a visão popular); tampouco será a história da vida de indivíduos comuns em situações de crises extremas (a visão de Sartre sobre a literatura por via de regra); e seguramente não será a história privada das grandes figuras históricas [...] Ele pode incluir todos esses aspectos, mas tão-somente sob a condição de que eles tenham sido organizados em uma oposição entre o plano público ou histórico (definido seja por costumes, eventos, crises ou líderes) e um plano existencial ou individual representado por aquela categoria narrativa que chamamos de personagens (JAMESON, 2004, p. 192).

Fredric Jameson apresenta certa preocupação com o modelo reconstitutivo de história, ou seja, com a ação de "preencher lacunas" dos fatos que as fontes documentais não demonstram. Neste sentido, a noção de verdade histórica deve ser vista "não pela via da verificação ou mesmo da verossimilhança, mas sobretudo por meio do poder imaginativo do falso e do factício, das mentiras e do engodo fantástico" (JAMESON, 2004, p. 201). Portanto, de acordo com as suas ideias, o romance histórico é um 
complemento do discurso histórico e deve ser lido como tal.

Para complementar as ideias de Jameson, Regina Dalcastagné comenta justamente que o discurso histórico não pretende ser objetivo. Pensar no passado com os pés no presente é estar rodeado de incertezas, pois os acontecimentos "nos legam principalmente lacunas e silêncios. [...] O diálogo da literatura com a história vai se tornando cada vez mais importante, já que tanto uma quanto a outra têm consciência de sua necessidade mútua" (DALCASTAGNÉ, 1996, p. 48).

A visão marxista de Lukács explicita que a importância não reside na noção de história como pano de fundo da narrativa, mas no impacto dos dados históricos no homem comum. György Lukács defende a ideia de que o romance histórico é necessariamente social e, assim, poderia, inclusive, evidenciar a tensão entre as classes sociais. Partindo das ideias acerca da forma clássica de romance histórico, a proposta de Lukács apresenta, sinteticamente, as seguintes características:

1. o romance histórico autêntico - cujo modelo é Walter Scott - narra a história como crise, penetrando na essência da época (as forças sociais em disputa);

2. os personagens são construídos como tipos histórico-sociais, havendo sempre um resgate da humanidade dos mesmos;

3. o herói surge a partir da crise, da essência mesma dos acontecimentos;

a fidelidade histórica é fator importante nesse romance.

4. Mas a teoria de Lukács sobre o romance histórico, embora muito bem fundamentada, não deixa de ser alvo de críticas (FERNANDES, 2012, p. 89, grifos do autor).

Como a leitura do trecho acima deixa entrever, os critérios de romance histórico propostos por Lukács já não conseguem dar conta de toda a ficção contemporânea. Surgem, então, novas propostas para olhar a relação entre literatura e história como, por exemplo, a proposta do livro Novo romance histórico da América Latina (1979-1992), de Seymour Menton (1993), o livro Meta- História: A Imaginação Histórica do Século XIX de Hayden White (1973) e o termo "metaficção historiográfica" do livro Poética do PósModernismo: história, teoria e ficção (1988), de Linda Hutcheon.

Seymour Menton parte de um corpus literário específico para definir o que seria o novo romance histórico, pois ele trabalha apenas com romances publicados na América Latina. Sua pesquisa demonstra que o primeiro novo romance histórico é O reino deste mundo, de Alejo Carpentier (1949) e que este tipo específico de romance obteve seu auge na década de 70 . Porém, há uma problemática em seu conceito: ao propor o "novo" romance histórico, Menton não realiza nenhuma reflexão crítica acerca do conceito de romance 
histórico de Lukács, algo que foi severamente criticado por Grützmacher (2006).

Aliás, ao definir características para o novo romance histórico e indicar a intertextualidade como uma delas, Seymour Menton não está postulando nada inovador, pelo contrário, a própria teoria lukacsiana já a utilizava, pois não existiria conceito de "romance histórico" sem postular a relação entre a literatura e a história. Além disso, independente do adjetivo "histórico", há o entendimento de que todo romance é intertextual, pois ele faz parte e está em contato com a cultura escrita. Quando Menton tenta diferenciar o novo romance histórico da teoria de Lukács, ele faz afirmações vagas, como a de que "la NNH [Nueva Novela Histórica] se distingue de la novela histórica tradicional por su mayor variedade" (MENTON, 1993, p. 45). A proposta de Menton, portanto, realiza uma distinção superficial da teoria lukacsiana, se limitando apenas a discutir que o autor precisava narrar algo distante de seu tempo e, assim, suas ideias causam mais confusão do que esclarecimento (GRÜTZMACHER, 2006).

Para Perry Anderson (2007), a difusão de romance histórico pósmoderno encontra justificativa na produção dos escritores latino-americanos e, por irônica coincidência, ele cita $\mathrm{O}$ reino deste mundo, de Alejo Carpentier (1949) como um texto germinal. Para o pesquisador, o romance histórico é produzido na atualidade bem mais do que em seu período clássico, o século XIX. Porém, ele sofre reformulações demandadas pelo próprio pósmodernismo:

todas as regras do cânone clássico, tais como explicitadas por Lukács, são desprezadas e invertidas. Entre outros traços, o romance histórico reinventado para pós-modernos pode misturar livremente os tempos, combinando ou entretecendo passado e presente; exibir o autor dentro da própria narrativa; adotar figuras históricas ilustres como personagens centrais, e não apenas secundárias; propor situações contrafactuais; disseminar anacronismos; multiplicar finais alternativos [...] (ANDERSON, 2007, p. 06).

Ainda no que se refere especificamente ao romance histórico contemporâneo da América Latina, pode-se dizer que são textos que retomam

[...] os relatos sobre a conquista, sobre a colonização/dizimação dos índios, sobre as guerras de independência, sobre o embate civilização x barbárie, e sobretudo trazendo perfis de grandes ditadores, esse romance não deixa de abordar nossa identidade. Mas, diferentemente do séc. XIX, costurando os fatos a partir de múltiplas perspectivas e desconstruindo as versões oficiais pela paródia (FERNANDES, 2012, p. 95).

Da citação acima, pode-se observar que o uso do conceito de paródia já 
nos remete ao termo "metaficção historiográfica". Ao propor uma poética do pós-modernismo, Hutcheon argumenta que a metaficção historiográfica "não pretende reproduzir acontecimentos, mas, em vez disso, orientar-nos para os fatos, ou para novas direções a tomar [...]" (HUTCHEON, 1991, p. 198).

No que diz respeito à metaficção historiográfica, Marilene Weinhardt afirma que "[...] já não se confunde com a ficção histórica por comportar uma aguda autoconsciência de seu processo de constituição" (1994, p. 58). A partir das ideias de Hutcheon, não há um consenso definitivo acerca do que definimos como pós-modernismo. Portanto, pode ser considerado como um momento contraditório, paradoxal e questionador, ou seja, não possui uma definição exata, é algo fluído.

A partir das ideias de Linda Hutcheon, não há um consenso definitivo acerca do que definimos como pós-modernismo. Portanto, este pode ser considerado um momento contraditório, paradoxal e questionador, ou seja, não possui uma definição exata, é algo fluído. Do mesmo modo que o PósModernismo "[...] é fundamentalmente contraditório, deliberadamente histórico e inevitavelmente político" (HUTCHEON, 1991, p. 20), o termo metaficção historiográfica demonstra que há questionamentos sobre a forma como a história está sendo escrita.

Rafaella Berto Pucca (2007) concorda com as opiniões de Hutcheon, pois situa o pós-modernismo não apenas como um movimento estético, mas como um acontecimento histórico, político e econômico. A partir do pósmodernismo, a história passa a ser descrita "como narrativa de acontecimentos que podem conter mais de um ponto de vista" (PUCCA, 2007, p. 06).

O próprio repensar a historiografia está vinculado ao fato de visualizar a história como algo da criação humana e acessá-la na forma textual: "O pósmodernismo não nega a existência do passado, mas de fato questiona se jamais poderemos conhecer o passado a não ser por meio de seus restos textualizados" (HUTCHEON, 1991, p. 39, grifos do autor). A partir dessa visão pós-moderna, o acesso ao entendimento da história está relacionado à ideia de que tanto a história como a ficção são discursos que possuem em comum a linguagem, traduzida em vestígios textuais.

Hutcheon afirma que a escrita pós-moderna expôs "que a ficção e a história são discursos, que ambas constituem sistemas de significação pelos quais damos sentido ao passado [...]" (1991, p. 122). Logo em seguida, esta afirmação é ampliada, pois a pesquisadora declara que o pós-modernismo desfaz toda e qualquer sacralização da arte, por isso a literatura passa a ser uma das várias possibilidades de representação do real e é tão paradoxal justamente 
por não ter compromisso nenhum com a realidade. Hutcheon, ao estabelecer o conceito de metaficção historiográfica, não está propondo a destruição do termo "história", mas sim uma fluidez de barreiras entre as áreas, ou seja, “[...] uma tentativa de inserir uma nova historicidade e uma nova problematização de conhecimento histórico" (HUTCHEON, 1991, p. 274).

No prefácio do livro Meta-História: A Imaginação Histórica do Século XIX, Hayden White afirma que "[...] o historiador realiza um ato essencialmente poético" (2008, p. 12, grifos do autor). Esta avaliação, como se sabe, é significativa, afinal, as narrativas históricas (assim como as literárias) constituem-se pela linguagem cuja característica principal é a falibilidade. White afirma que as possíveis formas de aproximação entre literatura e história ocorrem a partir de técnicas linguísticas e, a partir desta constatação, questiona o objetivo e status da história como disciplina, afinal, "[...] as disputas sobre o que a "história" deve ser refletem de igual modo variadas concepções daquilo em que deve consistir uma correta explicação histórica e diferentes concepções, portanto, da tarefa do historiador" (WHITE, 2008, p. 28).

Uma informação que não pode passar despercebida é o seguinte fato: o leitor do livro de Hayden White está lendo sua tese de doutorado, orientada pelo professor Northrop Frye, da área da literatura. A publicação do livro em 1973 coincide com o período da chamada "virada linguística", momento em que a linguagem torna-se central como construção da história e viabiliza a aproximação das práticas discursivas - literatura e história - no que elas têm em comum: a produção pela linguagem. Além disso, a "virada linguística" é um momento de questionamento sobre a visão de arte e, nesse caso, a literatura é considerada como uma opção entre as várias possibilidades de representação do mundo.

Ao definir a crônica, a estória, o modo de elaboração de enredo, o modo de argumentação e o modo de implicação ideológica como os níveis de conceptualização da obra histórica, White faz a seguinte consideração:

As distinções entre crônica, estória e enredo que tentei expor nesta seção talvez
tenham mais valia para análise de trabalhos históricos do que para o estudo de
ficções literárias. Ao contrário de ficções literárias como o romance, as obras
históricas são feitas de acontecimentos que existem fora da consciência do
escritor. Os acontecimentos relatados num romance podem ser inventados de
um modo que não podem ser (ou não devem) ser inventados numa história
(WHITE, 2008, p. 21)

No trecho, o historiador tece comentários para pensar em limites nas análises existentes entre a área histórica e a literária. Entretanto, o uso do "talvez" na explicação já nos leva para outro caminho: ele deixa a afirmação 
em aberto, no campo das possibilidades. Por conseguinte, White avança sua leitura sobre as narrativas históricas e ressalta que não deve ser realizado um apagamento da importância da invenção na tarefa do historiador. Desse modo, o que ocorre é um rompimento com o pensamento clássico, no qual os historiadores não poderiam preencher ausências textuais com a imaginação.

Aliás, se fôssemos pensar na literatura contemporânea, no percurso inverso, ou seja, o escritor que realiza uma intensa pesquisa histórica para realizar sua ficção, teríamos como exemplo o romance A Festa do Bode, de Mario Vargas Llosa (2000). Este romance contextualiza o período da Era Trujillo (1930-1961), na República Dominicana, de uma forma que muitos documentos históricos não o fariam.

A partir das ideias de White, a linguagem é praticamente uma palavrachave, pois é considerada como o meio essencial para a construção das narrativas históricas. Ao fazer a descrição dos métodos historiográficos, White questiona a existência da "Verdade", afinal, existem várias possibilidades de verdades interpretativas, visto que há uma imensa dificuldade em definir o que vem a ser uma verdade histórica, factual.

Hutcheon afirma que, apesar de divergirem em algumas ideias, os estudos de Jameson e White acerca da relação entre literatura e história estão relacionados com as ideias da metaficção historiográfica, já que ambos trabalham

\footnotetext{
a respeito do discurso histórico e de sua relação com o literário as mesmas questões levantadas pela metaficção historiográfica: questões como as da forma narrativa, da intertextualidade, das estratégias de representação, da função da linguagem, da relação entre o fato histórico e o acontecimento empírico, e, em geral, das consequências epistemológicas e ontológicas do ato de tornar problemático aquilo que antes era aceito pela historiografia - e pela literatura como uma certeza (HUTCHEON, 1991, p. 14).
}

A literatura, como sabemos, trabalha com a ideia de verossimilhança, isto é, se assemelha com o real (compromisso evidente com a ficção), enquanto a história trabalha textualmente com certa noção de verdade. É discutível pensar em verdade absoluta, pois a ideia de que a história é contada pelos vencedores passa a ser questionada no século XX, já que cada fato pode possuir diversas versões, dependendo das fontes documentais utilizadas ou até mesmo do posicionamento ideológico do narrador. Além disso, a história deve ser vista como "[...] um movimento inconcluso, eternamente sujeito a revisões" (DALCASTAGNÉ, 1996, p. 47).

Paul Sutermeister afirma ser necessário o questionamento do valor da 
verdade na historiografia, afinal, “[...] os acontecimentos históricos não têm como ser abordados tal qual aconteceram” (SUTERMEISTER, 2009, p. 47). Cabe ressaltar que um fato aparentemente só existe enquanto vivência/experiência e, no momento de traduzir este fato em código escrito, o sujeito possivelmente já se inscreve no campo ficcional.

Ainda a respeito do valor da verdade na historiografia e na ficção, Mario Vargas Llosa afirma que "En efecto, las novelas mienten - no pueden hacer otra cosa - pero ésa es sólo una parte de la historia. La otra es que, mintiendo, expresan una curiosa verdad, que sólo puede expresarse disimulada y encubierta, disfrazada de lo que no es"3 (2002, p. 5). Vargas Llosa explica que na ficção a verdade é sempre subjetiva e relativa, visto que a literatura, pela liberdade de seu espaço de criação artística, pode contar uma história que a escrita dos historiadores não tem acesso.

No livro Desconstruindo a História, o historiador Alun Munslow levanta a seguinte questão: "[...] até que ponto a história, enquanto disciplina, pode recuperar e representar com precisão o conteúdo do passado através da narrativa" (MUNSLOW, 2009, p. 10). Munslow propõe que repensemos a história para percebê-la como uma criação que se apresenta para os leitores na forma de uma narrativa escrita.

Esta afirmação se aproxima das ideias de Hayden White a respeito da importância da invenção na tarefa do historiador e da necessária utilização de elementos poéticos na historiografia. Como já foi possível perceber o diálogo entre o que White e Munslow pensam sobre as narrativas históricas, não surpreende quando lemos que o objetivo do livro é "[...] destacar a natureza essencialmente literária do conhecimento histórico e a importância de sua forma narrativa na construção de tal conhecimento" (MUNSLOW, 2009, p. 12).

Outro ponto de ligação entre as teorias de White e Munslow está no fato dos dois historiadores perceberem o papel essencial da linguagem para a produção histórica. Entre as afirmações de Munslow, destaca-se a seguinte sobre as narrativas históricas:

Por não podermos ter acesso direto ao passado, seja como um movimento político, como um processo econômico ou como um evento, usamos a narrativa para exercer uma dupla função: como uma substituição do passado e como um

3 "De fato, os romances mentem - não podem fazer outra coisa - mas essa é só uma parte da história. A outra é que, mentindo, expressam uma curiosa verdade, que só pode se expressar dissimulada e encoberta, disfarçada do que não é" (2002, p. 5, tradução nossa). 
meio de negociação em nosso comprometimento ativo com o passado. A história é, dessa forma, uma aula de literatura (MUNSLOW, 2009, p. 14).

Ao posicionar suas constatações no contexto do pós-modernismo, Munslow abre espaço para questionamentos sobre a natureza da história e sua representação do passado. Munslow prefere utilizar o termo pós-modernismo sem hífen em seu livro. Para o autor, "Entre os princípios-chave dessa nova condição do conhecimento estão as grandes dúvidas que agora existem sobre a exata representação da realidade" (MUNSLOW, 2009, p. 10). A intenção deste texto não é entrar nesta discussão, por isso será mantido o termo pósmodernismo, pois, com ou sem hífen, retrata o momento de questionamentos infindáveis.

Para os historiadores tradicionais, a questão da legitimidade é crucial. De acordo com Lyotard (1988), é possível inferir que o pós-modernismo é o momento que possibilita ao sujeito o questionamento sobre as grandes narrativas (uma delas é a própria história). A questão da legitimidade suscita outra reflexão, presente também no texto de Lyotard: a verdade absoluta não existe. Essa afirmação coincide com o fato de que toda e qualquer possibilidade de reconstrução histórica é passada pelo filtro de quem escreve, ou seja, o historiador/narrador.

Por outro lado, os historiadores conscientes de seu trabalho com a linguagem (a chamada "consciência desconstrutiva" no texto de Munslow) e da representação através da linguagem de fatos que não vivenciaram, sabem que a narrativa histórica precisa ser coesa e coerente, e esta é uma questão textual, não do domínio da história. História e linguagem são, portanto, interdependentes.

Para reforçar suas ideias, Munslow traz para a discussão (além do já citado Jean-Françoise Lyotard), Michel Foucault e Roland Barthes. O conceito "morte do autor", cunhado por Barthes, é mencionado para refletir sobre a impossibilidade de sabermos a intenção dos autores das fontes com as quais o historiador opera: "[...] a importância do autor é minimizada na medida em que ele é visto como representativo de outros textos e posições ideológicas e não como aquele que origina o significado" (MUNSLOW, 2009, p. 87).

Assim como Lyotard aborda a questão do poder e da centralidade de informação, Foucault também analisa as relações de poder na sociedade. Munslow, a partir de ecos de Foucault, comenta que "[...] a narrativa é um discurso cuja circulação é poder" (2009, p. 91). Na conclusão do livro, Munslow reitera que é necessário desfazer a crença de que podemos conhecer completamente os acontecimentos do passado através dos textos produzidos 
pelos historiadores: "O passado não é descoberto ou achado. Ele é criado e representado pelo historiador como um texto que, por sua vez, é consumido pelo leitor" (MUNSLOW, 2009, p. 234).

Qualquer texto (seja ele histórico, literário, etc.) é passível de múltiplas interpretações, mas especificamente no caso da narrativa histórica isto fica ainda mais evidente, pois não temos acesso ao passado exatamente como ele foi, mas a versões textuais do passado:

A noção de que se não podemos recuperar a história do passado, então podemos experimentar diferentes histórias, desagrada os reconstrucionistas, inquieta a grande maioria dos construcionistas e, em geral, é bem aceita pelos desconstrucionistas (MUNSLOW, 2009, p. 99).

Em síntese, Munslow nos convida a questionar e redimensionar o produto do trabalho do historiador, isto é, as narrativas. Nesta perspectiva, o livro Lembrar Escrever Esquecer, também solicita que lembremos a "preciosa ambiguidade do próprio conceito de história, em que se ligam, indissociavelmente, o agir e o falar humanos: em particular a criatividade narrativa e a inventividade prática" (GAGNEBIN, 2006, p. 43, grifos do autor). Como mencionado anteriormente, os conceitos sofrem formulações incessantemente, e não seria diferente com a literatura e a história, duas áreas que indubitavelmente se ligam pelo fato de serem produzidas através da linguagem e publicadas em formato textual.

Fruto de intensa pesquisa histórica, a estrutura narrativa do romance $\mathrm{A}$ Festa do Bode é formada por eixos em paralelo que estão organizados da seguinte maneira: inicialmente é apresentado o eixo com maior teor literário (eixo da personagem Urania Cabral); nos outros dois eixos há uma aproximação maior com os dados históricos oficiais (eixos de Trujillo e dos revolucionários que planejam a morte do ditador, respectivamente). Os três eixos narrativos são criações ficcionais, porém, o eixo de Urania Cabral é ficcional por excelência, enquanto o eixo de Trujillo e dos revolucionários contextualizam o que aconteceu "de fato" como, por exemplo, o assassinato de Trujillo em 30 de maio de 1961.

Em A Festa do Bode, o eixo narrativo de Urania Cabral é o único situado no tempo presente, que equivale ao ano de 1996 na narrativa. Os outros dois eixos estão situados nos últimos dias da ditadura de Trujillo, entrelaçados pelo fatídico 30 de maio de 1961, que corresponde à data do assassinato do ditador. No que tange à recriação literária do perfil de grandes ditadores - uma temática constantemente presente nas pesquisas de representações literárias das ditaduras na América Latina - o romance A Festa 
do Bode dedica um eixo narrativo inteiro para dar voz a Trujillo, em seus últimos dias de vida.

A Festa do Bode, ao apresentar um eixo narrativo focalizado em Trujillo, realiza intertexto com o chamado "romance de ditador" (NAVARRO, 1989) da literatura hispano-americana. Além disso, a estratégia de representação de Trujillo está em consonância com uma atitude metaficcional, pois subverte a figura histórica que é recriada ora humanizada, ora mitificada.

Ainda no que se refere ao romance de Vargas Llosa, cabe ressaltar que "É precisamente o escritor quem tem a possibilidade de modelar, reconstruir e recordar por meio de sua criação estética, que muitas vezes se vincula a elementos históricos" (UMBACH, 2010, p. 110). Em consonância com as ideias de Umbach (2010), Márcia Hoppe Navarro afirma o seguinte:

Quando perspectivas históricas e/ou fatos históricos são emprestados para servir de estrutura a um projeto literário, o que deveria ser ressaltado, preliminarmente, é que toda obra literária constitui-se numa produção artística. [...] Por mais que um romancista procure expressar a realidade de maneira objetiva, sua obra será sempre subjetiva (NAVARRO, 1989, p. 18).

A pesquisadora Ana Cuiñas (2005) argumenta que este é um romance que amplia a visão do que é considerado histórico, principalmente por dar voz àqueles que não são ouvidos pela história oficial, noção desenvolvida pelos estudos no campo da metaficção historiográfica:

La fiesta del Chivo [...] es narrada "desde abajo", polifónica, e intenta captar múltiples perspectivas sobre el pasado, ampliando la visión de lo que es considerado como histórico - la vida privada, lo cotidiano -; es uno de los caminos que han encontrado las novelas históricas para recuperar el pasado no canonizado, dándole lugar a las voces desoídas por la "historia oficial" que aportan aspectos fundamentales en la constitución de las identidades colectivas4 (CUIÑAS, 2005, p. 26).

A personagem Urania Cabral representa essa coletividade, pois é a voz que seria desprezada pela história oficial. Também funciona, no romance, como a recriação ficcional das vítimas do período repressivo que sofreram experiências traumáticas. Além disso, Urania estabelece uma relação com a

4 “A Festa do Bode é narrada 'de baixo', polifônica, e tenta captar múltiplas perspectivas sobre o passado, ampliando a visão do que é considerado como histórico a vida privada, o cotidiano -; é um dos caminhos que os romances históricos encontraram para recuperar o passado não canonizado, dando lugar às vozes não ouvidas pela 'história oficial' que proporcionam aspectos fundamentais na constituição das identidades coletivas" (CUIÑAS, 2005, p. 26, tradução nossa). 
tarefa de historiador, pois ao residir nos Estados Unidos e cortar os laços familiares durante 35 anos, o único vínculo que não rompe com a República Dominicana é justamente o textual: “[...] naqueles anos de Cambridge contraíra o "hobby perverso": ler e colecionar livros sobre a Era Trujillo" (LLOSA, 2011, p. 179).

A atitude metaficcional está presente na conversa, ou nas interrupções, que o narrador onisciente mantém com Urania através do monólogo interior. Quando a personagem rememora sua inocência, antes de ser entregue para Trujillo pelo próprio pai, o narrador sempre acrescenta comentários aos seus pensamentos: "Mas ela era uma menina normal e saudável — o último dia que você seria assim, Urania —, devoradora de romances [...]" (LLOSA, 2011, p. 306).

Gagnebin também comenta que a tarefa do narrador ou do historiador precisa estar focada justamente naquilo que a história oficial não consagra a devida relevância: "o narrador e o historiador deveriam transmitir o que a tradição, oficial ou dominante, justamente não recorda. Essa tarefa paradoxal consiste, então, na transmissão do inenarrável [...]" (GAGNEBIN, 2006, p. 54). O eixo narrativo dos conspiradores demonstra exatamente esse tipo de narrativa, em que a dor se faz presente, como se vê na descrição da tortura que Salvador Estrella Sadhalá presenciou na prisão El Nueve:

De todos os relatos dos companheiros de cela, ficou gravada em Salvador, como
marca indelével, uma história que Modesto Díaz contou soluçando. Durante as
primeiras semanas, ele dividiu a cela com Miguel Ángel Báez Díaz. Abbes
García e Ramfis tinham se encarniçado contra ele, por ter sido tão próximo de
Trujillo, assistindo às sessões de choque, açoite e queimadura que lhe infligiam e
ordenando aos médicos do SIM que o reanimassem, para continuar. Duas ou
três semanas depois, em vez do habitual prato fedorento de farinha de milho,
trouxeram para o calabouço uma panela com pedaços de carne. Miguel Ángel
Báez e Modesto quase engasgaram, comendo com as mãos até se fartar. Pouco
depois, o carcereiro voltou a entrar. Olhou para Báez Díaz: o general Ramfis
Trujillo queria saber se não lhe dava nojo comer o próprio filho. [...] Miguel
Ángel Báez Díaz morreu horas depois, nos braços de Modesto, de um ataque
cardíaco (LLOSA, 2011, p. 378).

Tavares (2007) reconhece que o romance de Vargas Llosa reúne, lado a lado, criação artística e o resgate histórico não apenas do contexto, mas das figuras históricas da época, como é o caso de Trujillo e Joaquín Balaguer. Ao falar das técnicas narrativas do romance, a pesquisadora afirma que Vargas Llosa retoma um capítulo histórico vivido factualmente pelos dominicanos entre 1930 e 1961 (a ditadura da Era Trujillo) e inter-relaciona diferentes vozes discursivas que dão conta não só do conhecimento histórico, mas do campo 
ficcional, caso de Urania Cabral que, através de seu trauma, representa as mulheres que sofreram nas mãos do déspota e de Agustín Cabral, seu pai, representante do círculo de subservientes fiéis de Trujillo que, mesmo caindo em desgraça, não realiza vingança alguma contra o Generalíssimo.

É por meio dessas diversas vozes narrativas compostas, de um lado, pelas vozes que não fariam parte do discurso histórico oficial (eixo narrativo de Urania e dos revolucionários) e, por outro lado, pela voz autorizada da história oficial, Trujillo, que se constata: "Romances pós-modernos, confirmam, abertamente, que só existem verdades no plural [...]" (LANIS, 2005 , p. 36). Ao olhar para um fato histórico, o ficcionista tem a possibilidade de trabalhar paralelamente com múltiplos discursos que não apenas confrontam um ao outro, mas também dialogam.

Um exemplo disso é a descrição do assassinato de Trujillo no romance, narrado bifocalmente: pela versão do próprio ditador e também pelo ponto de vista dos revolucionários. Em 30 de maio de 1961, o ditador estava prestes a chegar à Casa de Caoba, pois havia ordenado que seus capangas encontrassem Yolanda Esterel, de dezessete anos, para a prática de mais um estupro. Trujillo não imaginava que esta ida à Casa de Caoba seria interrompida e, desta vez, para sempre:

Vagamente, percebeu que um carro buzinava atrás. Estava com os faróis altos
acesos. - Esses bêbados... - comentou Zacarías de la Cruz. Nesse instante,
Trujillo pensou que talvez não fosse um bêbado e virou-se em busca do revólver
que tinha no assento, mas não conseguiu pegá-lo, e ao mesmo tempo ouviu a
explosão de um fuzil cujo projétil estilhaçou o vidro da janela de trás e arrancou
um pedaço do seu ombro e do braço esquerdo (LLOSA, 2011, p. 334).

O tão almejado sonho dos revolucionários de ver Trujillo morto havia se tornado fato. É no capítulo XXII, dedicado a Salvador Estrella Sadhalá, que nos é descrita, pela visão justamente daquele que participou do complô para matar o ditador, a cena de Trujillo morto:

Durante cinco, oito, dez segundos, houve um silêncio absoluto. Como numa fantasmagoria, Salvador notou que, pela pista da sua direita, passavam rumo a Trujillo dois carros, a toda velocidade. Um momento depois, outro estrondo de tiros de fuzil e revólver. Demorou poucos segundos. Então, o vozeirão de Antonio de la Maza encheu a noite: - Está morto, porra! Ele e Amadito começaram a correr. Segundos depois, Salvador parava, avançava a cabeça sobre os ombros de Tony Imbert e Antonio, que, um com um isqueiro e outro com palitos de fósforos, examinavam o corpo banhado em sangue, vestido de verde oliva, o rosto destroçado, que jazia no pavimento sobre uma poça de sangue. A Besta, morta (LLOSA, 2011, p. 220).

No romance de Vargas Llosa há a recuperação de "informações acerca 
dos acontecimentos atrozes ocorridos em nome da ditadura [...]" (TAVARES, 2007, p. 189). Antonio Imbert, revolucionário infiltrado nas mobilizações para derrubar Trujillo, comenta sobre o Movimento 14 de Junho, ocorrido em 1959, quando um avião de Cuba pousou em solo dominicano com guerrilheiros antitrujillistas, expondo que Fidel Castro apoiava o fim de Trujillo. Além disso, esta tentativa de derrubar Trujillo contou com a ajuda massiva de estudantes oriundos da classe média dominicana, pessoas que nos anos de glória do Trujillato o apoiavam e agora tentavam exterminá-lo. Os guerrilheiros foram caçados e torturados, como se lê a seguir:

Os caliés levavam qualquer suspeito para o SIM, onde o submetiam a torturas
- como castrá-lo, perfurar seus ouvidos ou seus olhos, sentá-lo no Trono-
para que falasse nomes. As prisões de La Victoria, La Cuarenta e El Nueve
ficaram abarrotadas de jovens de ambos os sexos, estudantes, profissionais
liberais e funcionários públicos, muitos dos quais eram filhos ou parentes de
gente do governo. [...] Não ia deixar que arrancassem suas unhas com alicate,
cortassem sua língua ou o sentassem no trono elétrico. Podiam matá-lo, sim;
humilhá-lo, jamais. [...] pela primeira vez nos vinte e nove anos do regime,
apavorando as famílias da classe média, tradicionais pilares de Trujillo, de onde
saiu a maior parte de prisioneiros do que passou a ser chamado, por causa da
invasão frustrada, de Movimento 14 de Junho (LLOSA, 2011, p. 157-158).

A Festa do Bode pode ser considerada como um romance histórico pós-moderno, pois questiona a própria escrita da história oficial. Os três eixos narrativos dialogam, complementam o discurso um do outro e tem reflexos na constituição dos fatos. Não é apenas a versão oficial da história da Era Trujillo que interessa, mas todas as vozes subjetivas que recriam as versões não oficiais, representadas pela voz de Urania e dos conspiradores. Portanto, é um romance que questiona o passado e outras questões, a saber: "Todas essas questões subjetividade, intertextualidade, referência, ideologia - estão por trás das relações problematizadas entre a história e a ficção no pós-modernismo" (HUTCHEON, 1991, p. 155).

Perry Anderson (2007) afirma que atualmente se produz mais romance histórico do que no tempo de seu auge, o século XIX, analisado por Lukács. Porém, esse "ressurgimento" do romance histórico está atrelado ao pósmodernismo e ao boom de ficções históricas produzidas a partir de 1970 pelos escritores da América Latina. Segundo ele, tais ficções que comumente utilizam como pano de fundo as ditaduras militares funcionam também "como uma tentativa desesperada de nos acordar para a história, em um tempo em que morreu qualquer senso real" (ANDERSON, 2007, p. 07, grifos do autor).

Ainda a respeito do romance hispano-americano, Bella Josef abre seu livro com uma reflexão a respeito das transformações pelas quais o gênero 
literário romance já passou, impossível de conceituá-lo de forma estanque, pois tudo depende do contexto no qual foi produzido. Além disso, ela afirma que "O romance nasce da História, mas a transcende. Como forma particular da narrativa, é um dos modos de apreensão da realidade" (JOSEF, 1974, p. 15). Indubitavelmente, o romance aqui analisado está associado aos pressupostos pós-modernos de romance, afinal,

A ficção não reflete a realidade, nem a reproduz. Não pode fazê-lo. $\mathrm{Na}$ metaficção historiográfica não há nenhuma pretensão de mimese simplista. Em vez disso, a ficção é apresentada como mais um entre os discursos pelos quais elaboramos nossas versões da realidade, e tanto a elaboração como sua necessidade são o que se enfatiza no romance pós-modernista (HUTCHEON, 1991, p. 61).

Enquanto o historiador trabalha com uma intenção de veracidade, cabe ao ficcionista o compromisso com a verossimilhança. Ambos - o historiador e o escritor - trabalham com narrativas e certos graus de subjetividade, afinal, os historiadores atuais sabem que é inviável captar o todo de acontecimentos históricos. A linguagem, por meio da qual se produzem narrativas, aproxima o trabalho deles. A visão pós-modernista acentua que "a ficção é apresentada como mais um entre os discursos pelos quais elaboramos nossas versões da realidade [...]" (HUTCHEON, 1991, p. 64).

\section{Referências}

ANDERSON, Perry. Trajetos de uma forma literária. Novos Estudos / CEBRAP, São Paulo, n. 77, p. 01-08, 2007. Disponível em: $<$ http://www.scielo.br/scielo.php?script=sci_arttext\&pid=S0101$33002007000100010>$ Acesso em: 20 abr. 2017.

CUIÑAS, Ana Gallego. Trujillo: el fantasma y sus escritores (Análisis y sistematización de la novela del Trujillato). 2005. Tese (Doutorado em Literatura Espanhola) - Universidade de Granada, Granada, 2005. Disponível em: <http://hera.ugr.es/tesisugr/15346511.pdf> Acesso em: 10 abr. 2017.

DALCASTAGNÉ, Regina. O espaço da dor. O regime de 64 no romance brasileiro. Brasília: Editora Universidade de Brasília, 1996.

FERNANDES, Rinaldo de. Vargas Llosa, um Prêmio Nobel em Canudos: ensaios de literatura brasileira e hispano-americana. Rio de Janeiro: Garamond, 2012. 
GAGNEBIN, Jeanne Marie. Lembrar escrever esquecer. São Paulo: Editora 34, 2006.

GRÜTZMACHER, Lukasz. Las trampas del concepto "la nueva novela histórica" y de la retórica de la historia postoficial. Acta Poética, México, D.F, v. 27, n.1, pp. 141-168, 2006. Disponível em: <http://132.248.101.214/htmldocs/acta-poetica/27-1/141-168.pdf> Acesso em: 10 abr. 2017.

HUTCHEON, Linda. Poética do pós-modernismo: história, teoria, ficção. Traduzido por Ricardo Cruz. Rio de Janeiro: Imago Ed., 1991.

JAMESON, Fredric. O romance histórico ainda é possível? Novos Estudos, São Paulo, v. 77, p. 185-203, 2007. Disponível em: http://www.scielo.br/scielo.php?script=sci_arttext\&pid=S010133002007000100009 Acesso em: 20 abr. 2017.

JOSEF, Bella. O espaço reconquistado: linguagem e criação no romance hispano-americano contemporâneo. Petrópolis: Vozes, 1974.

LANIS, Cláudia Paulino. A obra de Mario Vargas Llosa, La Fiesta del Chivo, e a multiplicidade de máscaras. 2005. 134 f. Dissertação (Mestrado em Letras Neolatinas, Língua Espanhola e Literaturas Hispânicas) - Programa de Pós-Graduação em Letras Neolatinas, Universidade Federal do Rio de Janeiro, Rio de Janeiro, 2005. Disponível em: $<$ http://www.dominiopublico.gov.br/esquisa/DetalheObraForm.do?select_a ction $=\&$ co_obra $=35838>$ Acesso em: 10 abr. 2017.

LLOSA, Mario Vargas. A Festa do Bode. Rio de Janeiro: Objetiva/Alfaguara, 2011.

LLOSA, Mario Vargas. La verdad de las mentiras. Madrid: Alfaguara, 2002.

LUKÁCS, György. O romance histórico. São Paulo: Boitempo, 2011.

LYOTARD, Jean-Françoise. O Pós-Moderno. Rio de Janeiro: José Olympio Editora, 1988.

MENTON, Seymour. La nueva novela histórica de la América Latina. México: Fondo de Cultura Económica, 1992.

MUNSLOW, Alun. Desconstruindo a História. Petrópolis, Rio de Janeiro: Vozes, 2009.

NAVARRO, Márcia Hoppe. O romance do ditador. Poder e história na América Latina. São Paulo: Ícone, 1989.

PUCCA, Rafaela Berto. O Pós-Modernismo e a revisão da História. Terra roxa 
e outras terras - Revista de Estudos Literários, Londrina, v. 10, p. 69-76, 2007. Disponível em: < http://www.uel.br/cch/pos/letras/terraroxa> Acesso em: 18 abr. 2016.

SUTERMEISTER, Paul. A meta-história de Hayden White: uma crítica construtiva à "ciência" histórica. Espaço Acadêmico, no 97 , p. 43-48, junho de 2009. Disponível em: <http://eduem.uem.br/ojs/index.php/ /EspacoAcademico/article/viewFile/7102/4141> Acesso em: 18 abr. 2017.

TAVARES, Carla Rosane da Silva. A perspectiva da mulher como resistência às configurações ideológicas do ditador latino-americano: $\mathrm{O}$ romance de Julia Alvarez e de Mario Vargas Llosa. 2007. Tese (Doutorado em Literatura Comparada) - Programa de Pós-Graduação em Letras, Universidade Federal do Rio Grande do Sul, Porto Alegre, 2007. Disponível em <http://www.lume.ufrgs.br/handle/10183/12752> Acesso em: 10 abr. 2017.

UMBACH, Rosani Ketzer. Literatura e história: os discursos da memória. Fragmentos, Florianópolis, n. 39, p. 105-119, 2010.

WEINHARDT, Marilene. Considerações sobre o romance histórico. Letras, Curitiba, n. 43, p. 49-59, 1994.

WHITE, Hayden. Introdução. A Poética da História. In: MetaHistória: a imaginação histórica do século XIX. São Paulo: Editora da Universidade de São Paulo, 2008.

\footnotetext{
Abstract: This article will expose about the interdependent relation between literature and history. Its object of analysis is the novel A Festa do Bode (2000), from Mario Vargas Llosa. By specifying the literary genre novel with the adjective "historical" it becomes apparent a tension, because literature and history are forms of expression of the knowledge initially considered different and opposite. Thus, as frequently occurs with the concepts of the Human Science area, it becomes difficult to find a watertight definition of historical novel, once the concepts of literature and history suffered - and will suffer - modifications along the time.
}

Keywords: literature; history; historical novel; historiografic-metafiction 